\title{
Mechanics of Work-related Back Pain: An Analytical Review
}

\author{
Omar S. Alsufyani ${ }^{* 1}$, Renad S. AlSufyani ${ }^{2}$, Abdulrahman E Altowairqi ${ }^{3}$, Tethkar M. AlTowairqi ${ }^{4}$, \\ Mohammed H. Altowairqi ${ }^{5}$
}

${ }^{1}$ General Practitioner, Jazan Military Hospital, Jazan, Saudi Arabia, Omar.seraj@hotmail.com

${ }^{2}$ General Practice, Emergency Department, Prince Mansour Military Hospital, Taif, Saudi Arabia, renad.seraj@gmail.com

${ }^{3}$ Family Medicine Specialist, Department of Family Medicine, Prince Mansour Military Hospital, Taif, Saudi Arabia, Drabdulrahman313@gmail.com

${ }^{4}$ Medical Intern, College of Medicine, Taif University, Taif, Saudi Arabia,Tethkartw1417@gmail.com

${ }^{5}$ General Surgery Resident, Department of General Surgery, King Abdul Aziz Specialist Hospital, Taif, Saudi Arabia, Mo.Altowairqi@gmail.com

*Corresponding Author: Omar S Alsufyani; omaralsufyani@outlook.com

Received 05 December 2021;

Accepted 21 December 2021;

Published 26 December 2021

\begin{abstract}
The prevalence of Low back pain (LBP) is exceedingly high, upwards of $80 \%$ in the general population. LBP is manifested as pain in the thoraco-lumbar area and often related to a muscle pull. This paper is a narrative review of the mechanics of work-related low back pain. In this paper, the researchers provide a different insight of the occupational low back pain as they introduce a theoretical background of the occupational low back pain and management of low back pain at workplace. In addition, the study highlight the research focus within the field of mechanical loading and biomechanical assessment methods of low back pain. The study found that low back pain is a reversible process in case causes are identified. However, it is a challenging issue to identify the causes unless well-designed models and assessment methods are applied for each case separately.
\end{abstract}

Keywords: Low back pain, work-related back pain, Mechanics, Orthopedic

\section{Introduction}

Low back pain (LBP) is considered to be a significant musculoskeletal disorder, ${ }^{[1]}$ and it might be to be referred as low back disorders because a lot of information that highlight the significance of this problem at workplace are coming from epidemiological studies where this problem is defined differently ranging from trouble or discomfort at lower back to an actual injury in the lower back ${ }^{[2]}$. So, stemming from these epidemiological studies, it is clear that low back disorder is very prevalent at workplace, and there are reports in terms of lifetime prevalence of low back disorders to be as high as $80 \%$, like suggesting that pretty much most of workers experience low back disorder viewing their work life ${ }^{[3]}$.

Looking at labor statistical data, it could be observed that occupations and jobs that are associated are very physically demanding, the incidence of low back pain disorder is high among them, ${ }^{[4]}$ but again equally low back pain is seen and reported in occupations that are not physically demanding and pretty much sedentary ${ }^{[5]}$. As far it relates to the cost associated with low back disorder at workplace or cost associated with missed work days, productivity loss, and if there is requirement for replacing their workers, there is going to be cost associated with worker replacement ${ }^{[6]}$.

Prevention of low back disorder at workplace is an extremely challenging task and that is primarily because the exact cause of low back disorder cannot be determined ${ }^{[7]}$. In such situation, the majority or the most of the prevention efforts at workplace are focused on managing the known risk factors or work-related risk factors for low back disorders ${ }^{[8]}$. These risk factors can be categorized at being like work-related and non-work related. Among the non-work related risk factors there are risk factors that are essentially personal risk factors ${ }^{[9]}$. For example, gender was identified as a risk factor for low back disorders because of the evidence that suggests that the risk of experiencing low back disorder is higher among females as compared to males 
${ }^{[10]}$. On the other hand, the work-related factors can be categorized as either being physical risk factors or psychosocial risk factors ${ }^{[11]}$. For instance, whole body vibration is a known risk factor for experiencing low back disorder ${ }^{[12]}$. On the side of the psychosocial risk factor, a number of factors have been identified, such as stress, job clarity, and social support ${ }^{[13]}$. These are considered to be known and established risk factors that have been associated with low back disorder. So, in the absence of any knowledge about the exact cause of like different low back disorders that are observed, pretty much preventive efforts are being focused on managing exposure to these risk factors ${ }^{[14]}$.

From a clinical perspective, low back disorder is significant primarily at tis chronic stage and low back pain is considered or defined as chronic depending based on the duration of time that symptoms has been present ${ }^{[14,15]}$. There are different definitions out there in terms of what chronic, non-chronic, acute, or sub-acute is low back pain but the most recent definition by the National Institute of Health (NIH) suggests that if the symptoms have been present for more than the time during the past six months, the low back pain can be considered as chronic low back pain. At its chronic stage, low back pain is considered to be a leading cause of disability, it is also associated with opioid abuse ${ }^{[13,16]}$.

Also, similar to prevention challenge, treatment of low back pain is challenging because in most low back pain cases that are seen by physicians, it is not possible to determine what is causing that specific back pain case and they are being categorized as nonspecific low back pain ${ }^{[17]}$. So, in this situation, there are a number of treatments available and pretty much the effects of these treatments on a given patients is being guided by the symptoms and by the effects on the level of pain and disability ${ }^{[3,18]}$. However, a good thing regarding the clinical perspective is that the clinical course of low back pain is pretty much for most of individuals is favorable and after a few weeks they get recovered regardless of what type of treatment they are receiving ${ }^{[19]}$.

The American College of Physicians and the American Pain Society released a guideline flow chart for treatment of patients with low back pain ${ }^{[20]}$. Early on this guideline, a given patient is being screened for known or specific source of pain as well as like to rule out any red flag. Once that is done, the patient is categorized as non-specific, meaning that the specific cause cannot be determined ${ }^{[21]}$. The practice will involve asking the patient to stay active and get pain medications if needed and then if the patient is not getting better, the patient will get into a trial and error report where they are being given different types of treatment hopefully they respond to one of these treatments ${ }^{[22]}$.

\section{Management of low back pain at workplace}

When current condition in terms of management of low back pain, whether at workplace or clinically is as follow ${ }^{[23]}$. At workplace, preventive efforts are primarily focused on managing exposure to risk factors. For example, to reduce or eliminate exposure to risk factor ${ }^{[19]}$. The treatment efforts are primarily guided by the impact of treatment on the symptom and then we look at systematic reviews with the result coming from systematic reviews of intervention that have been performed for preventing low back disorder at workplace or look at the efficacy of treatment offered for low back pain ${ }^{[21]}$. Clinically, the outcome of the systematic reviews are not satisfactory. One reason for such unsatisfactory outcome is a lack of knowledge about the link(s) between exposure to risk factors (receiving treatment) and experience of low back pain. This gap is an area that scholars are trying to contribute currently in research ${ }^{[15]}$.

\section{Research Focus}

To clarify more about research focus, it is significant to bring attention to that in an individual's experience of low back pain, there is going to be three important element. One is going to be a source of pain, a second is a sensing element, and also the third is interpretation that is happening inside the person's brain. So, what scholars are mostly concerned in their research is that the low back pain are the social problems that is located inside the low back pain [24]. Specifically, scholars are mostly concerned primarily with potential source of pain within the lower back pain and like actually mechanical source of pain and that is because lower back tissues are very well innervated tissues particularly as related to the spinal cord. Inter-verbal discs and facet joins are all innervated structures and there are evidence out there that shows mechanical loads, excessive force, excessive deformation can either directly and indirectly stimulate these pain sensitive nerve endings or result in experience of low back pain ${ }^{[25]}$.

Scholars tried to provide an accurate estimation of quantification of lower back pain environment, the force and information that is being experienced in the lower back tissue, and as related to occupational low back pain, scholars are interested to see how workplace factors, the identified risk factors for low back disorder, affect mechanical environment inside the lower back tissues.

\section{Mechanical loading}

The loads that are experienced, force and deformation experience in the lower back tissue is directly determined by the equilibrium and stability status of the spinal cord ${ }^{[26]}$. A spine equilibrium is a balance between two sets of force; a force that is inserted on the spine by the internal trunk tissue muscles, passive tissue like ligaments and an external force making the other set of force that is due to the weight of the trunk, weight of the hands and head, and also if these structures are moving like fast or the inertial component forces due to initial demand of these components. If the person is having a physical interaction like lifting a load, the load, an inertial demand due to that is a manipulated load ${ }^{[27]}$. So, the balance between these two set of force around the spine is defined to be spine equilibrium. When an individual will perform an activity, they should generate enough muscle force to be able to perform that activity and because of the deformation of the spine that this other passive tissues that they cannot generate active force, they also being involved in like that equilibrium and these force inside them being considered load like loads inside the lower back tissue is being affected by the equilibrium of the spine ${ }^{[28]}$.

As related to the spine stability, the stability of the spine is defined as a quality of spine equilibrium, so there are different definitions for spinal stability in the literature or the clinical definition of stability is quite different and they are based on information coming from images obtained from patients, ${ }^{[29]}$ but what we define as a spine instability is the characteristics of spine equilibrium and that is the capacity of the system that provide equilibrium to the spine in sustaining that equilibrium condition despite internal and external perturbation ${ }^{[30]}$.

To explain more how stability of spine will affect the load experience inside the lower back tissues, of a person is required to lift a load from the floor, from an equilibrium perspective, ${ }^{[18]}$ if the person requires to generate enough force inside the muscle to be able to move the weight of the trunk, head, and hands, as well as the weight of that object, and then by going to being able to move them upward altogether. So the force inside these like muscles 
which determine the muscle forces, the first that are inside, the ligaments due to stretching will be like the force that is same, ${ }^{[15]}$ but in the passive tissue and the vector sum of this internal and external force will be representing a spinal force that is being seen like inside the spinal tissue, but if that object that is being lifted by the person (for example: unstable object filled with liquid), that as soon as it is being lifted from the ground, the liquid start moving around and just applying continuous perturbation to the system, then the system will adopt a stabilizing strategy, such as strengthening the core muscles by activating and co-activating, but not only activating the extensor muscles, but abdominal muscles. That strengthening of the core muscles, which result in the experience of much larger load as needed, simply satisfying the requirement of the spine ${ }^{[24]}$.

\section{Biomechanical Assessment Methods}

It is possible to do measurements of lower back tissue loads, but it is extremely difficult and are significant ethical considerations. Therefore, mechanical models have become much more attractive for researchers ${ }^{[31]}$.

Looking into the literature, there is a wide range of mechanical models that are being used for studying load in the lower back tissues. This range from simple rigid-body models that they provide information about the physical and mechanical demands of an activity and the lower back, and they do not provide information about the internal tissue response. Some of these rigidbody models are being integrated with some muscle models to just get some estimate of how much muscle force are needed to balance that mechanical requirement of the task ${ }^{[32]}$.

Then, a level higher, there are some models that in addition to muscle, also they recommends passive structures in equipment that will keep the spine. These models pretty much work on the basis of inverse dynamic method and the input to these models are motion and force measured during the experimentation, and the act is going to be the momentum at different level of lower back or spinal column, as well as most required muscle force or deformation or force generated by the passive tissues ${ }^{[22]}$. The majority of them are working on the basis of consideration of spine equilibrium. There are few studies that have considered stability requirements in estimating load in the side of the lower back ${ }^{[28]}$.

\section{Conclusion}

The present study concluded that the management of low back pain or low back disorder is a challenging task because of the inability to determine the exact cause of low back disorder for a given case or for a give patient, but there are a lot of information out there that shows forces and information inside the lower back tissues they can cause experience of back pain. There have been a lot of advances in recent years in terms of quantification or characterization of lower back mechanics that these can be implemented to better characterize the impact of workplace factors or treatments on lower back pain mechanics, and hopefully eventually implemented these knowledge to design effective interventions or more efficient treatments for low back pain treatment.

\section{References}

[1] Lopez-Lopez D, Vilar-Fernandez JM, Calvo-Lobo C, Losa-Iglesias ME, Rodriguez-Sanz D, Becerro-deBengoa-Vallejo R. Evaluation of depression in subacute low back pain: a case control study. Pain physician. 2017;20(4):E499-E505.

[2] Çınar-Medeni Ö, Elbasan B, Duzgun I. Low back pain prevalence in healthcare professionals and identification of factors affecting low back pain. Journal of back and musculoskeletal rehabilitation. 2017;30(3):451-9.

[3] McGill S. Low back disorders: evidence-based prevention and rehabilitation: Human Kinetics; 2015.

[4] Summers K, Jinnett K, Bevan S. Musculoskeletal disorders, workforce health and productivity in the United States. The center for workforced health and performance, Lancaster university. 2015.

[5] Samaei SE, Mostafaee M, Jafarpoor H, Hosseinabadi MB. Effects of patient-handling and individual factors on the prevalence of low back pain among nursing personnel. Work. 2017;56(4):551-61.

[6] Yang H, Haldeman S, Lu M-L, Baker D. Low back pain prevalence and related workplace psychosocial risk factors: a study using data from the 2010 National Health Interview Survey. Journal of manipulative and physiological therapeutics. 2016;39(7):459-72.

[7] Rasmussen CDN, Holtermann A, Bay H, Søgaard K, Jørgensen MB. A multifaceted workplace intervention for low back pain in nurses' aides: a pragmatic stepped wedge cluster randomised controlled trial. Pain. 2015;156(9):1786.

[8] Steffens D, Maher CG, Pereira LS, Stevens ML, Oliveira VC, Chapple M, et al. Prevention of low back pain: a systematic review and meta-analysis. JAMA internal medicine. 2016;176(2):199-208.

[9] Van Eerd D, Munhall C, Irvin E, Rempel D, Brewer S, Van Der Beek A, et al. Effectiveness of workplace interventions in the prevention of upper extremity musculoskeletal disorders and symptoms: an update of the evidence. Occupational and Environmental Medicine. 2016;73(1):62-70.

[10] Steenstra IA, Munhall C, Irvin E, Oranye N, Passmore S, Van Eerd D, et al. Systematic review of prognostic factors for return to work in workers with sub acute and chronic low back pain. Journal of occupational rehabilitation. 2017;27(3):369-81.

[11] Stewart Williams J, Ng N, Peltzer K, Yawson A, Biritwum R, Maximova $\mathrm{T}$, et al. Risk factors and disability associated with low back pain in older adults in low-and middle-income countries. Results from the WHO Study on Global AGEing and Adult Health (SAGE). PLoS One. 2015;10(6):e0127880.

[12] Bovenzi M, Schust M, Mauro M. An overview of low back pain and occupational exposures to whole-body vibration and mechanical shocks. 2017.

[13] Matsudaira K, Kawaguchi M, Isomura T, Inuzuka K, Koga T, Miyoshi K, et al. Assessment of psychosocial risk factors for the development of non-specific chronic disabling low back pain in japanese workers-findings from the Japan Epidemiological Research of Occupationrelated Back Pain (JOB) study. Industrial health. 2015:2014-0260.

[14] Kresal F, Suklan J, Roblek V, Jerman A, Mesko M. Psychosocial risk factors for low back pain and absenteeism among Slovenian professional drivers. Central European journal of public health. 2017. 
[15] Buchbinder R, van Tulder M, Öberg B, Costa LM, Woolf A, Schoene M, et al. Low back pain: a call for action. The Lancet. 2018;391(10137):2384-8.

[16] Schneider M, Haas M, Glick R, Stevans J, Landsittel D. A comparison of spinal manipulation methods and usual medical care for acute and Sub-acute low back pain: a randomized clinical trial. Spine. 2015;40(4):209.

[17] Patel ND, Broderick DF, Burns J, Deshmukh TK, Fries IB, Harvey HB, et al. ACR appropriateness criteria low back pain. Journal of the American College of Radiology. 2016;13(9):1069-78.

[18] Foster NE, Anema JR, Cherkin D, Chou R, Cohen SP, Gross DP, et al. Prevention and treatment of low back pain: evidence, challenges, and promising directions. The Lancet. 2018;391(10137):2368-83.

[19] Maher C, Underwood M, Buchbinder R. Non-specific low back pain. The Lancet. 2017;389(10070):736-47.

[20] Chou R, Deyo R, Friedly J, Skelly A, Hashimoto R, Weimer $\mathrm{M}$, et al. Nonpharmacologic therapies for low back pain: a systematic review for an American College of Physicians clinical practice guideline. Annals of internal medicine. 2017;166(7):493-505.

[21] Chou R, Gordon DB, de Leon-Casasola OA, Rosenberg $\mathrm{JM}$, Bickler S, Brennan $\mathrm{T}$, et al. Management of Postoperative Pain: a clinical practice guideline from the American pain society, the American Society of Regional Anesthesia and Pain Medicine, and the American Society of Anesthesiologists' committee on regional anesthesia, executive committee, and administrative council. The journal of pain. 2016;17(2):131-57.

[22] Verhagen AP, Downie A, Popal N, Maher C, Koes BW. Red flags presented in current low back pain guidelines: a review. European spine journal. 2016;25(9):2788-802.

[23] Petit A, Fouquet N, Roquelaure Y. Chronic low-back pain, chronic disability at work, chronic management issues. Scandinavian journal of work, environment \& health. 2015;41(2):107-10.

[24] Linton SJ, Nicholas M, Shaw W. Why wait to address high-risk cases of acute low back pain? A comparison of stepped, stratified, and matched care. Pain. 2018;159(12):2437-41.

[25] Grabovac I, Dorner TE. Association between low back pain and various everyday performances. Wiener klinische Wochenschrift. 2019;131(21):541-9.

[26] Koopman AS, Kingma I, Faber GS, de Looze MP, van Dieën JH. Effects of a passive exoskeleton on the mechanical loading of the low back in static holding tasks. Journal of biomechanics. 2019;83:97-103.

[27] Van Dieën JH, Reeves NP, Kawchuk G, Van Dillen LR, Hodges PW. Analysis of motor control in patients with low back pain: A key to personalized care? Journal of orthopaedic \& sports physical therapy. 2019;49(6):380-8.

[28] Lynders C. The critical role of development of the transversus abdominis in the prevention and treatment of low back pain. HSS Journal®. 2019;15(3):214-20.

[29] Moreno Catalá M, Schroll A, Laube G, Arampatzis A. Muscle strength and neuromuscular control in low-back pain: elite athletes versus general population. Frontiers in neuroscience. 2018;12:436.

[30] Russo M, Deckers K, Eldabe S, Kiesel K, Gilligan C, Vieceli J, et al. Muscle control and non-specific chronic low back pain. Neuromodulation: Technology at the Neural Interface. 2018;21(1):1-9.

[31] Tadano S, Tanabe H, Arai S, Fujino K, Doi T, Akai M. Lumbar mechanical traction: A biomechanical assessment of change at the lumbar spine. BMC musculoskeletal disorders. 2019;20(1):1-12.

[32] Koch C, Hänsel F. Non-specific low back pain and postural control during quiet standing-a systematic review. Frontiers in psychology. 2019;10:586.

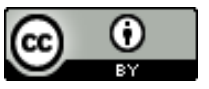

Open Access This article is licensed under a Creative Commons Attribution 4.0 International License, which permits use, sharing, adaptation, distribution and reproduction in any medium or format, as long as you give appropriate credit to the original author(s) and the source, provide a link to the Creative Commons license, and indicate if changes were made. The images or other third party material in this article are included in the article's Creative Commons license, unless indicated otherwise in a credit line to the material. If material is not included in the article's Creative Commons license and your intended use is not permitted by statutory regulation or exceeds the permitted use, you will need to obtain permission directly from the copyright holder. To view a copy of this license, visit https://creativecommons.org/licenses/by/4.0/.

(C) The Author(s) 2021 